\title{
Effect of Alumina Particles Addition on Physico-Mechanical Properties of AL-Matrix Composites
}

\author{
Moustafa M. M. Mohammed ${ }^{1}$, Omayma A. Elkady², \\ Abdelhameed Wazeer Abdelhameed ${ }^{3}$ \\ ${ }^{1}$ Faculty of Industrial Education, Beni-Suef University, Beni-Suef, Egypt \\ ${ }^{2}$ Powder Metallurgy Division, Manufacturing Department, Central Metallurgical Research and Development Institute, Cairo, Egypt \\ ${ }^{3}$ Production Department, Industrial Education College, Beni-Suef University, Beni-Suef, Egypt \\ Email: engmos_m2020@yahoo.com
}

Received September 25, 2013; revised October 25, 2013; accepted November 1, 2013

Copyright (C) 2013 Moustafa M. M. Mohammed et al. This is an open access article distributed under the Creative Commons Attribution License, which permits unrestricted use, distribution, and reproduction in any medium, provided the original work is properly cited.

\begin{abstract}
Metal-matrix composites (MMCs) are attracting considerable interest worldwide because of their superior mechanical and tribological properties. This study describes multifactor-based experiments that were applied to research and investigates Aluminum matrix composite reinforced with 5, $10 \& 15 \mathrm{wt} \%$ Alumina particles. Mechanical mixing technique was used for fabrication. Sintering was carried out in a vacuum furnace at $600^{\circ} \mathrm{C}$ for $1 \mathrm{hr}$. The effects of Alumina percentage on the density, microstructure, both electrical \& thermal conductivities, hardness and compression strength was investigated. The results showed that sample containing $5 \mathrm{wt} \%$ Alumina is near-fully dense. Also it has the highest hardness and compression strength.
\end{abstract}

Keywords: Al matrix Composites; Alumina Reinforcement; Mechanical Mixing; Thermal Conductivity; Electrical Conductivity; Mechanical Properties

\section{Introduction}

In the last decades, there is an increasing trend towards using composite materials, in order to achieve better performance in engineering materials [1]. Applications of AL-based metal matrix composite continue to expand for structural applications. Particularly in aerospace and automotive industries, owing to their low density, high thermal conductivity, high specific strength, stiffness, and better wear resistance resulting in considerable economic advantages [2-9]. Aluminum alloy has disadvantages as low hardness and poor wear resistance which are the main obstacles for their high performance tribiological applications [10,11]. Addition of ceramic oxide such as alumina reinforcement into ductile matrix such as Al affects greatly on both mechanical and physical properties of the produced composite [12-18]. During the last decades, enormous researches focused on hard ceramic particulate, fiber and whiskers reinforced aluminum metal which causes a modification of strength, stiffness, hardness, wear and fatigue resistance specially at elevated temperature applications. Those particularly improves cor- rosion resistance of the material, compared with conventional aluminum alloy [19-22]. The aim of this study is how to obtain a composite material of $\mathrm{AL}$ matrix with a uniform distribution of ceramic particles. $\mathrm{AL}_{2} \mathrm{O}_{3}$ is the most popular ceramic oxide that can be used as reinforcement due to its high stability at elevated temperatures that prevents its reaction with AL matrix [1]. There are several methods for fabrication of the Metal-Matrix Composites including mechanical milling, vortex process and ultra sonic cavitations, but all of these techniques are expensive because they need more energy. Powder metallurgy is a good technique in producing MMCs. Its main advantage is the low processing temperature than the melting technique, so there is no interaction between the matrix and the reinforcement. Also high homogenization between the two phases is achieved [23]. Another advantage is the fabrication of a near net shape product with low cost [24]. In this research, mixing of AL powder and $\mathrm{AL}_{2} \mathrm{O}_{3}$ particles was achieved and a uniaxial pressed was used to produce the composite samples. Physico-mechanical properties of the produced composites were investigated. 


\section{Material and Experimental Procedures}

\subsection{Mixing, Cold Compaction and Sintering}

In this research, AL powder with purity $99.99 \%$ and particle size $5-10 \mu \mathrm{m}$ was used as a matrix and reinforced with 5,10 , and $15 \mathrm{wt} \%$ of $\mathrm{AL}_{2} \mathrm{O}_{3}$ with $10 \mu \mathrm{m}$ particles size. Aluminum and alumina powders were investigated by SEM of model JEOL-JSM-4510, Development XRD diffractometer model Burcker D8 Advance with Ni filtered and $\mathrm{Cu}$ target in Central Metallurgical Research Institute (CMRDI) in Cairo. The powders were mixed with $0.5 \mathrm{wt} \%$ paraffin wax as a lubricant to reduce friction during compaction and liquid acetone was used as a process control agent, then dried at $80^{\circ} \mathrm{C}$ for $30 \mathrm{~min}$ and cold compacted at room temperature in a uniaxial press at $1060 \mathrm{Mpa}$. The samples were sintered in a vacuum furnace at $600^{\circ} \mathrm{C}$ for $1 \mathrm{hr}$ and a heating rate of $10^{\circ} \mathrm{C} / \mathrm{min}$.

\subsection{Composite Characterization}

Relative densities of the sintered samples were measured using Archimedes method using water as a floating liquid according to MPIF standard 42, 1998, in which the sintered specimen was weighed in air and in distilled water then the density $(D)$ was calculated according to the following equation:

$$
D=W_{a} /\left(W_{a}-W_{w}\right) \mathrm{g} / \mathrm{cm}^{3}
$$

Where,

$W_{a}$ and $W_{w}$ are the masses of the sample in air and water respectively. The theoretical densities $\left(D_{\mathrm{th}}\right)$ for the investigated materials were calculated according to the following equation:

$$
D_{\text {th }}=\left(V_{\mathrm{Al}} * D_{\mathrm{AL}}\right)+\left(V_{\mathrm{AL}_{2} \mathrm{O}_{3}} * D_{\mathrm{AL}_{2} \mathrm{O}_{3}}\right) \mathrm{g} / \mathrm{cm}^{3}
$$

Where,

$V_{\mathrm{AL}_{2} \mathrm{O}_{3}}$ is the volume fraction of alumina reinforcement,

$D_{\mathrm{AL}_{2} \mathrm{O}_{3}}$ is the density of $\mathrm{AL}_{2} \mathrm{O}_{3}$ equal $3.95 \mathrm{~g} / \mathrm{cm}^{3}$,

$V_{\mathrm{AL}}$ and $D_{\mathrm{AL}}$ are the volume fraction and density of the AL powder respectively. The degree of porosity of the sintered compacts was calculated according to the following equation:

$$
\text { Porosity } \%=\left(D_{\mathrm{th}}-D_{o}\right) / D_{\mathrm{th}} \%
$$

Where,

$D_{\text {th }}$ is the theoretical density of the sintered sample and $D_{o}$ is the actual density. Microstructure investigation was performed using both optical and scanning electron microscope using a JEOL JSM 5410-microscope. The diffraction patterns of the sintered samples were achieve by $\mathrm{x}$-ray diffraction analysis using $\mathrm{x}$-ray diffractometer model $\mathrm{x}$, pert PRO PANalytical with $\mathrm{Cu} \mathrm{k} \alpha$ radiation $(\lambda=$ $0.15406 \mathrm{~nm}$ ) The electrical resistivity of the sintered materials was measured using the four-probe method using
Omega CL1084 multimeter device, where the outermost two contacts were for passing D.C. current \& the inner two contacts were for measuring the potential difference.

A fixed DC current of one ampere was passed through the sample via two crocodile clips. For each test the multimeter was zeroed with no current passing the specimen, and then the measurement was carried out. The resistively $(\rho)$ was calculated according to the following equation:

$$
\rho=(R \cdot A) / L
$$

Where,

$R$ is the resistance in $\mathrm{m} \Omega, L$ is the measured length in $\mathrm{cm}$ and $A$ is the cross section area in $\mathrm{cm}^{2}$. The thermal conductivity of the composites was derived from the Wiedemann-Franz Law, which links the thermal conductivity to the electrical conductivity according to the following equation:

$$
K / \sigma=L \cdot T
$$

Where,

$K$ is the thermal conductivity in $\mathrm{W} / \mathrm{mK}, T$ is the absolute temperature in $K, \sigma$ is the electrical conductivity in $\Omega^{-1} \cdot \mathrm{m}^{-1}$, and $L$ is the Lorenz number, equal to $2.45 \times 10^{-8}$ $\mathrm{W} \Omega / \mathrm{K}^{2}$. Electrical conductivities of the polished samples were determined from the electrical resistivity measurements. The size of the samples used for testing is $32 \mathrm{~mm}$ $\times 11 \mathrm{~mm} \times 4 \mathrm{~mm}$ size. The electrical resistivity measured using Omega micro-ohmmeter in the two-probe mode. Vickers micro hardness was measured as the average of 5 readings along the cross section surface of the specimen using Vickers hardness tester by applying $4.9 \mathrm{~N}$ load and load time $10 \mathrm{sec}$. Compression strength test of investigated samples was also measured using uniaxial SHIMADZU universal testing machine UH-F500KN. The applied cross-head speed of universal test machine used in this study is $2 \mathrm{~mm} / \mathrm{min}$. The test was conducted at room temperature $\left(25^{\circ} \mathrm{C}\right)$.

\section{Results and Discussion}

\subsection{Powder Characterization}

(Figures 1(a) and (b)), show the experimental results of the XRD pattern of pure $\mathrm{AL}$ and $\mathrm{AL}_{2} \mathrm{O}_{3}$ powders respectively, which indicate the appearance of $\mathrm{AL}$ and $\mathrm{AL}_{2} \mathrm{O}_{3}$ peaks with high intensity that indicates the purity of the raw materials. (Figures 2(a) and (b)), show that the particle diameter of $\mathrm{AL}$ and $\mathrm{AL}_{2} \mathrm{O}_{3}$ was $5-10$, and 10 $\mu \mathrm{m}$ respectively.

\subsection{Composite Characterization}

\subsubsection{X-Ray Diffraction Analysis}

$\mathrm{X}$-ray diffraction was performed to determine the phase 

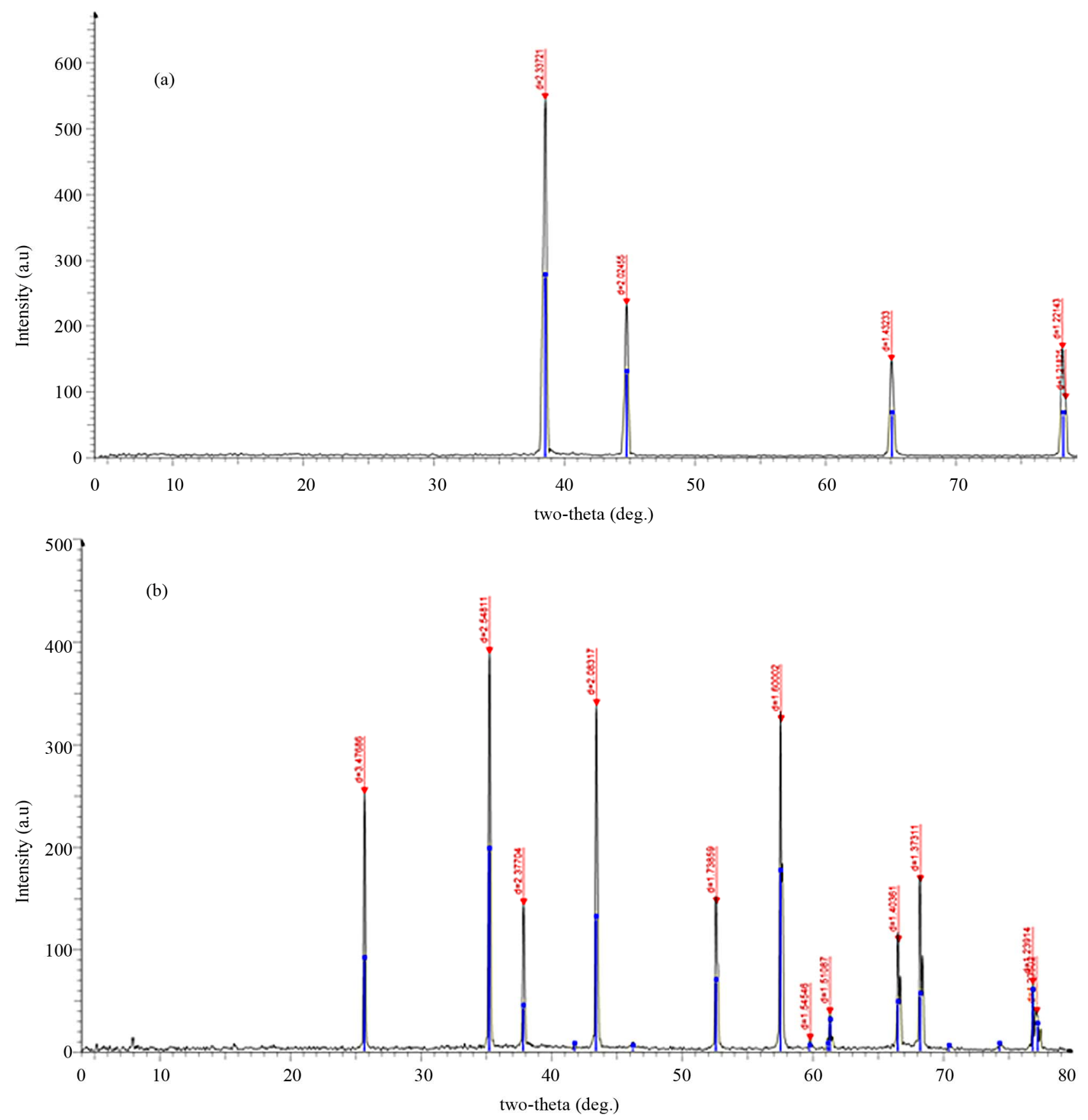

Figure 1. XRD pattern of: (a) $\mathrm{AL}$ and (b) $\mathrm{AL}_{2} \mathrm{O}_{3}$.

structure of the composites. Figure 3 show the XRD pattern of 5, 10 and $15 \mathrm{wt} \% \mathrm{AL}_{2} \mathrm{O}_{3}$.

It can be seen that the sintering process did not produce any new phases rather than face centered cubic structure with space group $\mathrm{Fm}-3 \mathrm{~m}, \mathrm{a}=0.40494$ for $\mathrm{AL}$ and corundum hexagonal bravais lattice, space group $\mathrm{R} 3 \mathrm{~m}, \mathrm{a}=\mathrm{b}=(3.079)$ and $\mathrm{c}=(67.996 \mathrm{~nm})$ for $\mathrm{AL}_{2} \mathrm{O}_{3}$ this means that the phases indicated by XRD analysis were similar for the three composites. The XRD pattern indicated that as the $\mathrm{AL}_{2} \mathrm{O}_{3}$ percent increases the intensities of the peaks that belongs to $\mathrm{AL}_{2} \mathrm{O}_{3}$ was increased and that of AL was slightly decreased. So from XRD charts there is no solid state reaction between $\mathrm{Al}$ and $\mathrm{AL}_{2} \mathrm{O}_{3}$ during the sintering process.

\subsubsection{Density}

Relative density of the composite is the ratio of the measured sintered density to the theoretical one. It was determined for pure $\mathrm{Al}$ and $\mathrm{AL}-\mathrm{AL}_{2} \mathrm{O}_{3}$ composites. The values of the relative density of $5,10 \& 15 \mathrm{wt} \% \mathrm{AL}$ - 

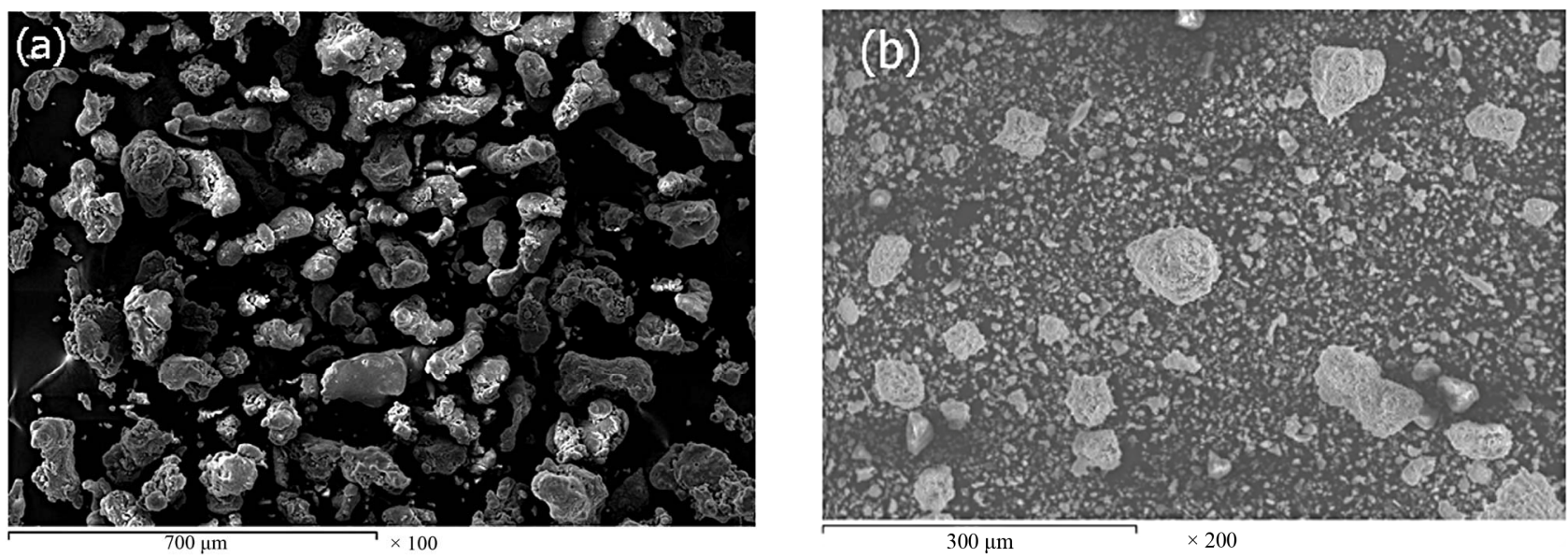

Figure 2. SEM Micrographs of: (a) $\mathrm{AL}$ and (b) $\mathrm{AL}_{2} \mathrm{O}_{3}$ powder.

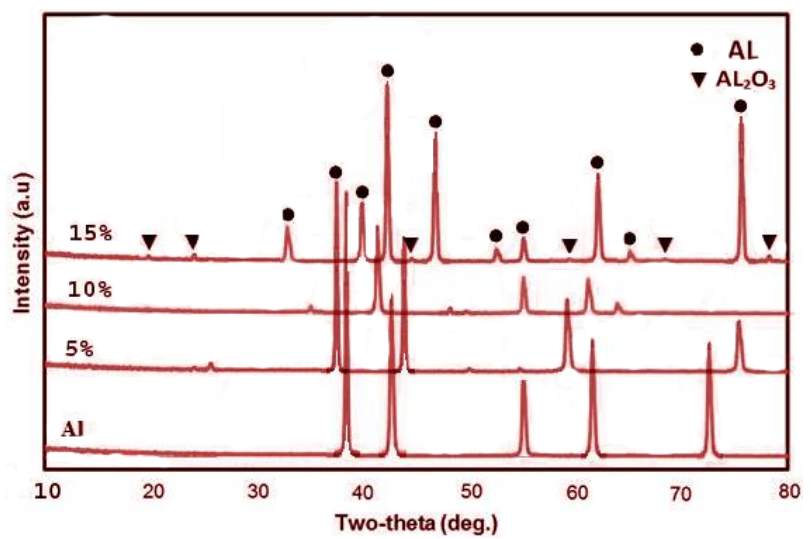

Figure 3. XRD pattern of pure Al \& 5, 10 \& 15 wt\% AL$\mathrm{AL}_{2} \mathrm{O}_{3}$ composite.

$\mathrm{AL}_{2} \mathrm{O}_{3}$ composites are shown in Table 1. This Table shows that the theoretical density increases by increasing the $\mathrm{AL}_{2} \mathrm{O}_{3}$ percent.

This can be attributed to the higher density of $\mathrm{AL}_{2} \mathrm{O}_{3}$ more than Al. Figure 4 indicates the experimental results for studying the relation between the relative density and alumina content. From this figure, the bulk density of 5 $\mathrm{wt} \% \mathrm{AL}_{2} \mathrm{O}_{3}$ was about $96.5 \%$ which is near fully density. This may be rationalized by the near ratio between the volume fraction of $5 \mathrm{wt} \% \mathrm{AL}_{2} \mathrm{O}_{3}$ and that of $95 \% \mathrm{AL}$. By increasing the $\mathrm{AL}_{2} \mathrm{O}_{3}$ percent the density decreases, this is due to the higher hardness of $\mathrm{AL}_{2} \mathrm{O}_{3}$ than that of $\mathrm{AL}$. It acts as a barrier network against consolidation that prevents the densification of the particles. Also increasing the $\mathrm{AL}_{2} \mathrm{O}_{3}$ percent leads to more contact between AL$\mathrm{AL}_{2} \mathrm{O}_{3}$ particles and so more intensive form appear [25]. The experimental results for investigating the relation between porosity and alumina content are shown in Figure 5. From this figure, the porosity of $\mathrm{AL}-\mathrm{AL}_{2} \mathrm{O}_{3}$ composites where $5 \mathrm{wt} \% \mathrm{AL}_{2} \mathrm{O}_{3}$ recorded $3.5 \%$ this mean that this sample is near full dense with higher density compared with the other samples.
Table 1. Relative density of 5, 10 \& $15 \mathrm{wt} \% \mathrm{AL}-\mathrm{AL}_{2} \mathrm{O}_{3}$ composites.

\begin{tabular}{cccc}
\hline Samples & $\begin{array}{c}\text { Sintering } \\
\text { Density }\end{array}$ & $\begin{array}{c}\text { Theoretical } \\
\text { Density }\end{array}$ & $\begin{array}{c}\text { Relative } \\
\text { Density \% }\end{array}$ \\
\hline $5 \% \mathrm{AL}_{2} \mathrm{O}_{3}$ & 2.648 & 2.74 & 96.5 \\
$10 \% \mathrm{AL}_{2} \mathrm{O}_{3}$ & 2.642 & 2.78 & 94.7 \\
$15 \% \mathrm{AL}_{2} \mathrm{O}_{3}$ & 2.596 & 2.83 & 91.6 \\
\hline
\end{tabular}

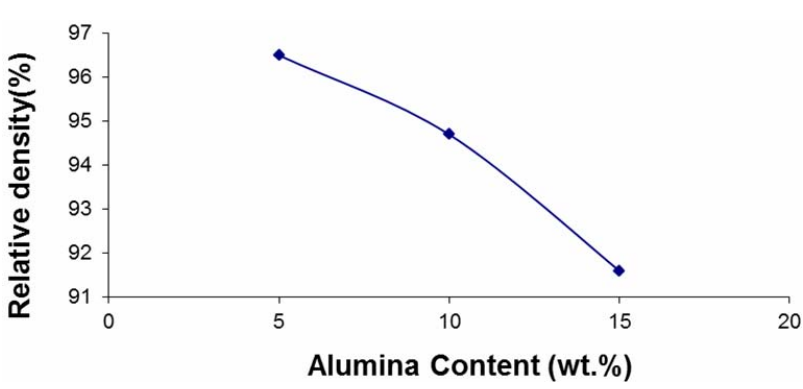

Figure 4. Relative densities of $\mathrm{AL}-\mathrm{AL}_{2} \mathrm{O}_{3}$ composites.

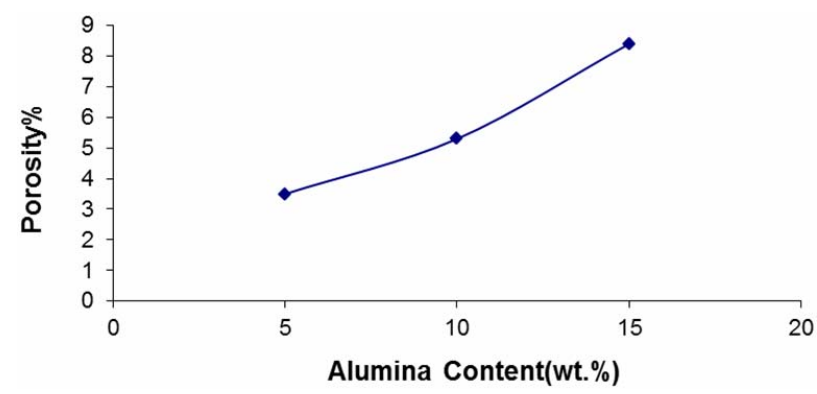

Figure 5. Porosity percent of $\mathrm{AL}-\mathrm{AL}_{2} \mathrm{O}_{3}$ composites.

\subsubsection{Microstructure of the Sintered Samples}

In order to study the micro structure changes of AL matrix by mixing with $\mathrm{AL}_{2} \mathrm{O}_{3}$ particles, both optical and scanning electron microscopes (SEM) were used. Figures 6(a)-(c) show the optical micrographs of $\mathrm{AL}-\mathrm{AL}_{2} \mathrm{O}_{3}$ sintered samples with $200 \times$ magnification.

Alumina particles are homogenously distributed all over the Al matrix. This may be due to the suitable mix- 
ing technique, time of mixing, compaction and suitable sintering temperature. SEM micrographs of pure $\mathrm{Al} \&$ $\mathrm{AL}-\mathrm{AL}_{2} \mathrm{O}_{3}$ samples were shown in Figures 7(a)-(d), with high magnifications and EDAX analysis for $10 \mathrm{wt} \%$ $\mathrm{AL}_{2} \mathrm{O}_{3}$.
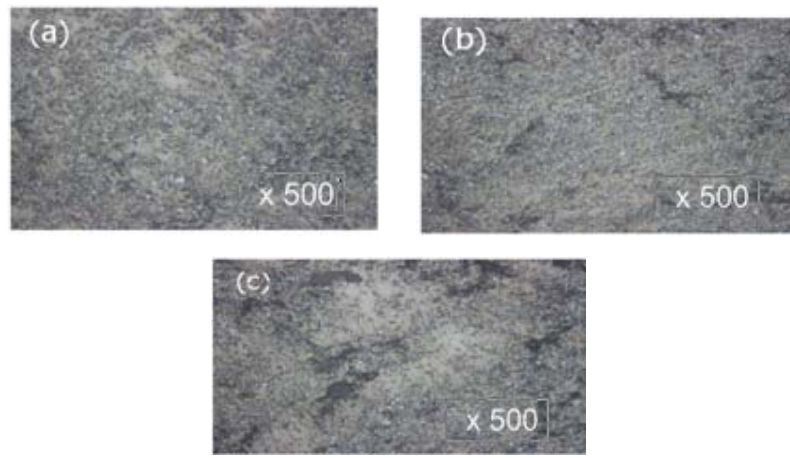

Figure 6. Optical micrographs of: (a) $\mathrm{AL}-5 \mathrm{wt} \% \mathrm{AL}_{2} \mathrm{O}_{3}$; (b) AL-10 wt $\% \mathrm{AL}_{2} \mathrm{O}_{3}$; and (c) AL-15 wt $\% \mathrm{AL}_{2} \mathrm{O}_{3}$.
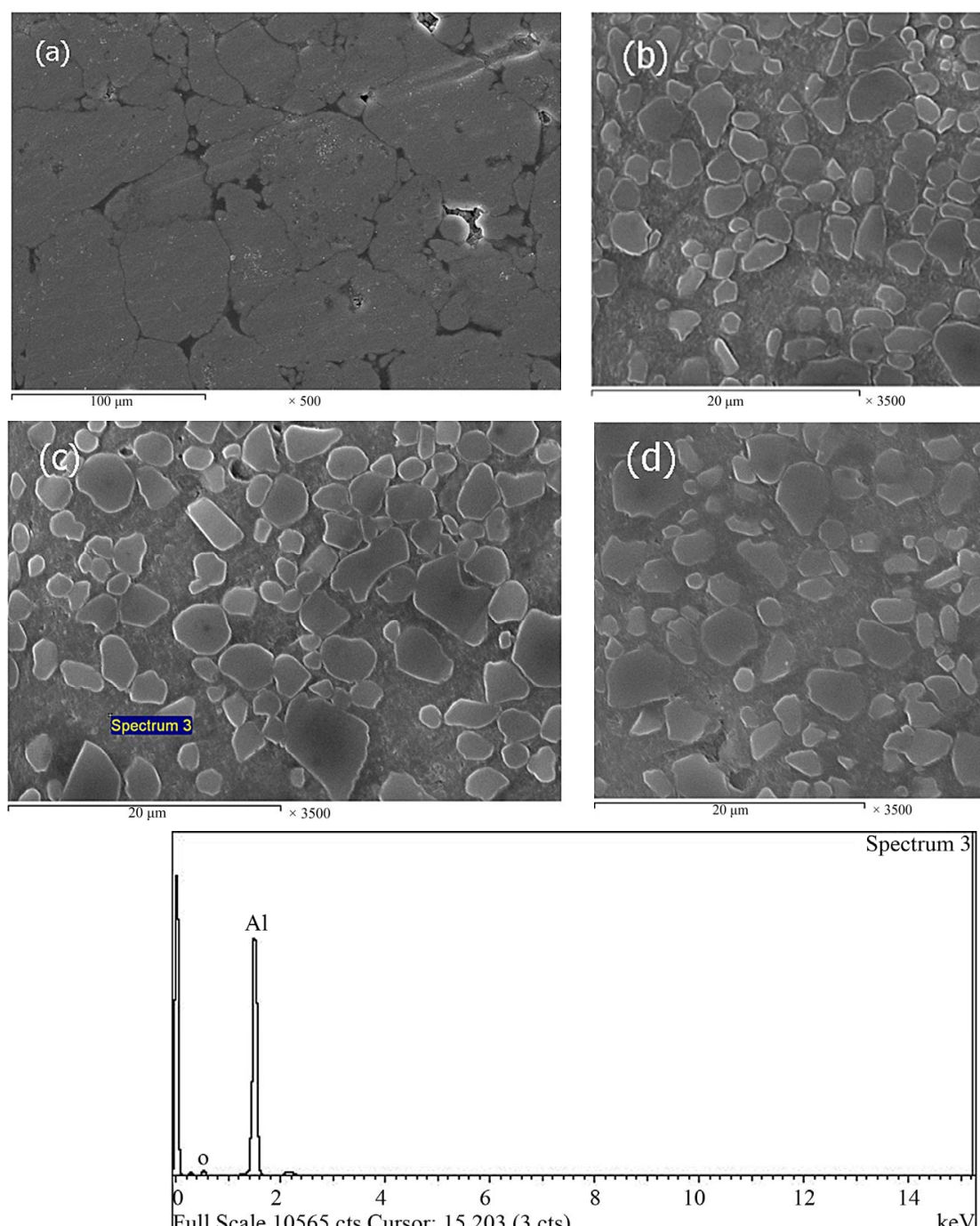

Figure 7. SEM Micrographs for (a) $\mathrm{AL}$; (b) $5 \mathrm{wt} \% \mathrm{AL}_{2} \mathrm{O}_{3}$; (c) $10 \mathrm{wt} \% \mathrm{AL}_{2} \mathrm{O}_{3}$; and (d) $15 \mathrm{wt} \% \mathrm{AL}_{2} \mathrm{O}_{3}$.
It was observed that the spectrum of $10 \mathrm{wt} \% \mathrm{AL}_{2} \mathrm{O}_{3}$ shows the presence of $\mathrm{AL}$ and oxygen elements which indicates that $\mathrm{AL}_{2} \mathrm{O}_{3}$ particles are dispersed into AL matrix with no other contamination. Both optical and SEM micrographs shows the homogeneous dispersion of $\mathrm{AL}_{2} \mathrm{O}_{3}$ in the $\mathrm{AL}$ matrix for the three $\mathrm{AL}-\mathrm{AL}_{2} \mathrm{O}_{3}$ composites. The micrographs contains three phases one of them is the gray matrix which is the AL matrix and the dispersed phase is the white spots which represents the $\mathrm{AL}_{2} \mathrm{O}_{3}$ particles and the third phase is the black spots that is the pores in the sintered samples which was performed by EDAX. Addition of more $\mathrm{AL}_{2} \mathrm{O}_{3}$ than $5 \mathrm{wt} \%$ causes the increasing of the internal porosity. This can be attributed to the poor wettability between the AL matrix and $\mathrm{AL}_{2} \mathrm{O}_{3}$ which causes aggregation of $\mathrm{AL}_{2} \mathrm{O}_{3}$ particles that distinct obstructed densification creating gaps that prevents the complete densification of the particles. The increasing of porosities is dark point which affects greatly on the mechanical properties such as hardness \& compression.
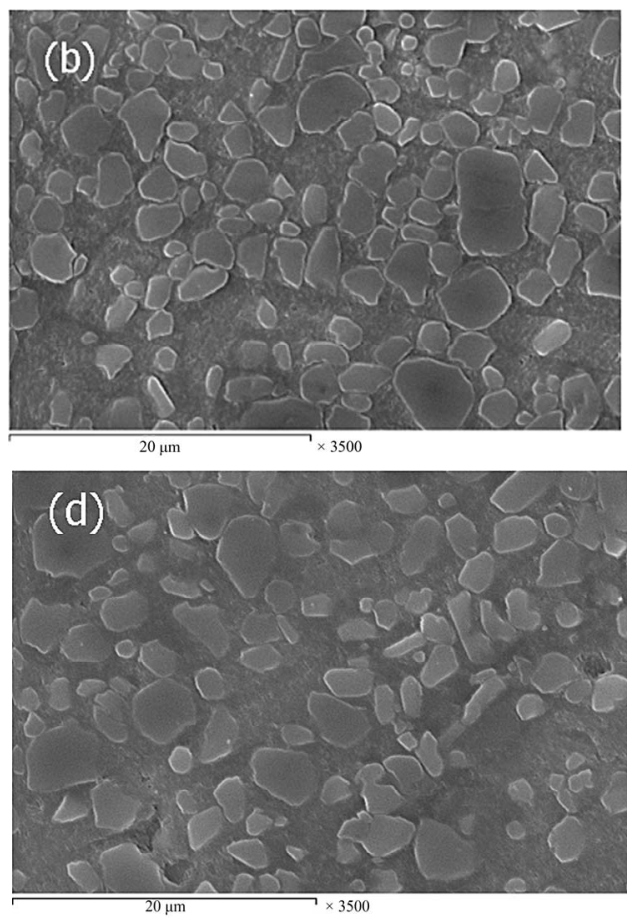


\subsubsection{Electrical Resistivity Measurement}

In this investigation, the electric resistance of the investigated samples was measured and converted to the electrical conductivity according to the ASTM standard B19372. Figure 8 and Table 2 show that the electrical resistivity increases by increasing the $\mathrm{AL}_{2} \mathrm{O}_{3}$ percent.

This is according to the lower conductivity value of $\mathrm{AL}_{2} \mathrm{O}_{3}$ more than that of $\mathrm{AL}$ that restricts the motion of the electrons which are responsible for the conductivity. Also the high porosity of the higher $\mathrm{AL}_{2} \mathrm{O}_{3}$ percent samples resulted from the weak bond and non-wettability between $\mathrm{AL}$ and $\mathrm{AL}_{2} \mathrm{O}_{3}$ creates voids that decrease the motilities of the free electrons causing a high resistivity [26].

\subsubsection{Thermal Conductivity Measurement}

Thermal conductivity is affected by many factors those are the conductivities of the constituents, reinforcement distribution, the volume fractions, shape \& size of the components, the interaction between the two phases and the method of preparation. The experimental results for investigating the relation between thermal conductivity and alumina content are shown in Figure 9. From this figure, the thermal conductivity of the composite decreases by increasing the $\mathrm{AL}_{2} \mathrm{O}_{3}$ percent. Also thermal conductivity is directly affected by the porosity, since the conductivity of a pore is zero so by increasing the $\mathrm{AL}_{2} \mathrm{O}_{3}$ content the pores increases and the thermal conductivity decreases. The relation between porosity and thermal conductivity is given by the following equation [27].

$$
k=K S(1-F)
$$

Where,

$k$ is the thermal conductivity (w/mk),

$K S$ is the intrinsic thermal conductivity, and

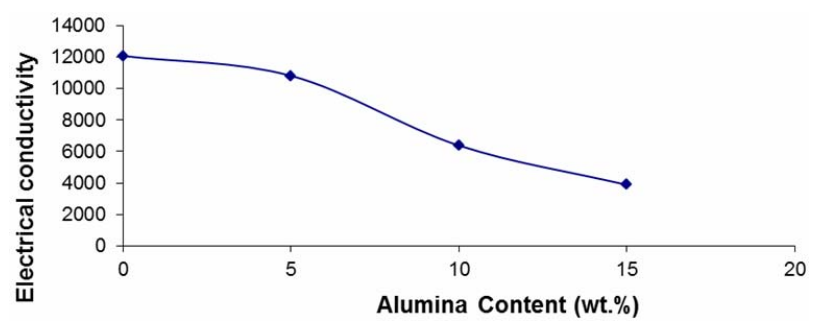

Figure 8. Electrical conductivity of pure AL \& 5, 10, and 15 wt $\% \mathrm{AL}_{2} \mathrm{O}_{3}$ composites.

Table 2. Electrical conductivity values for pure $\mathrm{Al} \& \mathbf{5 , 1 0}$ and $15 \mathrm{wt} \% \mathrm{AL}_{2} \mathrm{O}_{3}$.

\begin{tabular}{cc}
\hline Samples & Electrical Conductivity $\sigma=1 / \rho\left(\Omega^{-1} \cdot \mathrm{m}^{-1}\right)$ \\
\hline Pure & 12080.46243 \\
$5 \% \mathrm{AL}_{2} \mathrm{O}_{3}$ & 10822.51082 \\
$10 \% \mathrm{AL}_{2} \mathrm{O}_{3}$ & 6385.626701 \\
$15 \% \mathrm{AL}_{2} \mathrm{O}_{3}$ & 3882.847316 \\
\hline
\end{tabular}

$F$ is the fractional porosity. Also the nature of the ceramic $\mathrm{AL}_{2} \mathrm{O}_{3}$ particles that distort the structure forms barrier for the electrons which are responsible for thermal conductivities [28]. The values of Thermal conductivity for pure $\mathrm{Al} \& 5,10$ and $15 \mathrm{wt} \% \mathrm{AL}_{2} \mathrm{O}_{3}$ are shown in Table 3.

\subsubsection{Hardness Measurements}

Micro hardness of $\mathrm{Al}-\mathrm{AL}_{2} \mathrm{O}_{3}$ composites were shown in Figure 10 from this figure, it was clear that $5 \% \mathrm{AL}_{2} \mathrm{O}_{3}$ sample has the highest hardness due to the strengthening effect of the hard $\mathrm{AL}_{2} \mathrm{O}_{3}$ oxide ceramic, also the higher density and lower porosity of this sample. The presence of pores has a negative effect on the hardness. As the porosity of the samples increases by increasing alumina content the hardness decreases.

\subsubsection{Compression Test Measurement}

Figure 11 shows the results of compressive strength, from this figure it was evident that $5 \mathrm{wt} \% \mathrm{Al}_{2} \mathrm{O}_{3}$ sample has the highest compressive strength value more than that of $10 \& 15 \mathrm{wt} \% \mathrm{Al}_{2} \mathrm{O}_{3}$. This can be rationalized by the lower porosity of this sample than the other ones, in

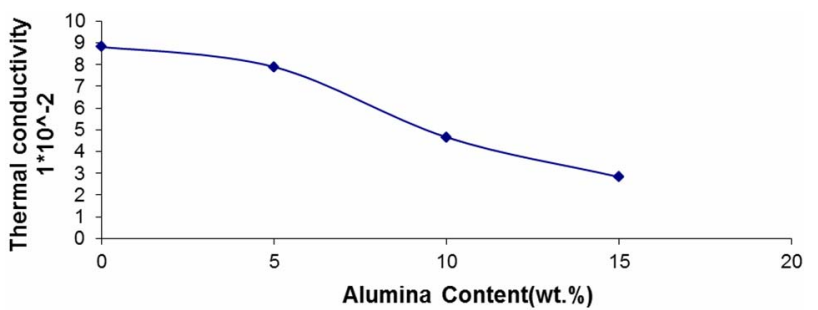

Figure 9. Thermal conductivity of pure AL \& 5, 10, and 15 wt $\% \mathrm{AL}_{2} \mathrm{O}_{3}$ composites.

Table 3. Thermal conductivity values for pure Al \& 5, 10 and $15 \mathrm{wt} \% \mathrm{AL}_{2} \mathrm{O}_{3}$.

\begin{tabular}{cc}
\hline Samples & Thermal conductivity $* 10^{-2} K=\sigma \cdot L \cdot T(\mathrm{~W} / \mathrm{m} \cdot \mathrm{K})$ \\
\hline Pure & 8.82 \\
$5 \% \mathrm{AL}_{2} \mathrm{O}_{3}$ & 7.90 \\
$10 \% \mathrm{AL}_{2} \mathrm{O}_{3}$ & 4.66 \\
$15 \% \mathrm{AL}_{2} \mathrm{O}_{3}$ & 2.83 \\
\hline
\end{tabular}

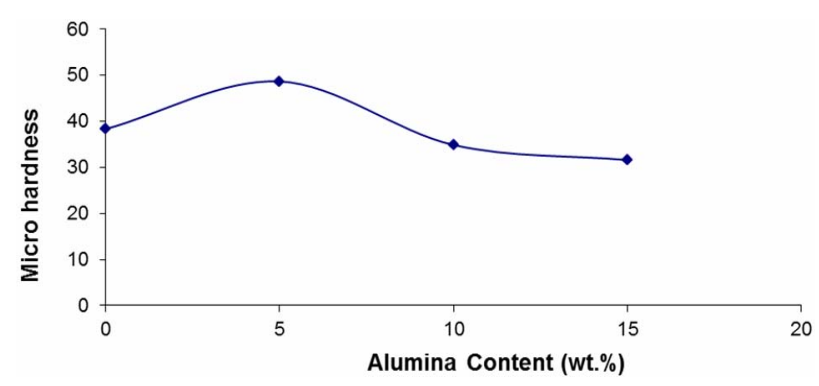

Figure 10. Micro hardness values as a function of $\mathrm{AL}_{2} \mathrm{O}_{3}$ percent. 


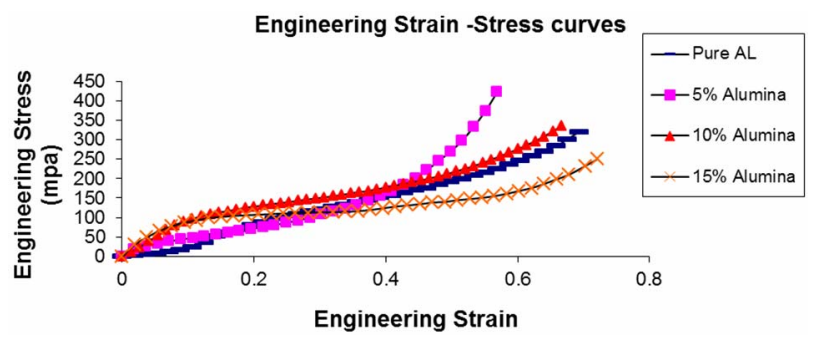

Figure 11. Compression test of Al pure \& 5, 10 \& 15 wt\% $\mathrm{AL}^{-\mathrm{AL}_{2}} \mathrm{O}_{3}$ composites.

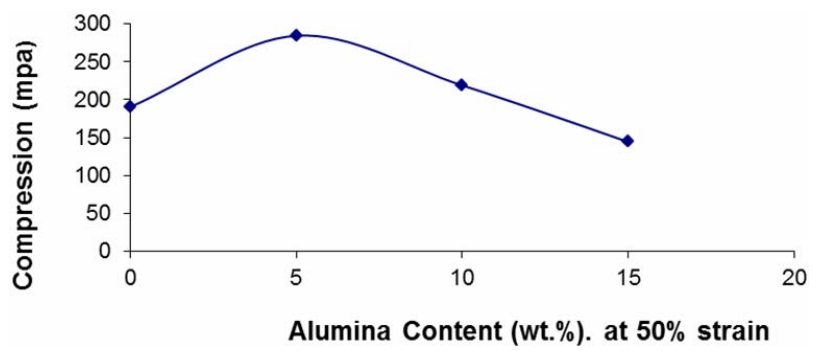

Figure 12. Compression test of Al pure \& 5, 10 \& $15 \mathrm{wt} \%$ $\mathrm{AL}-\mathrm{AL}_{2} \mathrm{O}_{3}$ composites at $\mathbf{5 0 \%}$ strain.

which the compressive strength increases by decreasing the porosity and increasing both the Al-content and density. The porosity of $\mathrm{Al}-\mathrm{Al}_{2} \mathrm{O}_{3}$ composite increases by increasing $\mathrm{Al}_{2} \mathrm{O}_{3}$ content this is considered a suitable site for crack nucleation and growth where the stress may concentrate [29]. Figure 12 shows the compressive strength at 50\% strain. From (Figures 11 and 12), the higher compression strength value was for $5 \mathrm{wt} \%$ sample which is in agreement with the above results.

\section{Conclusions}

According to the above mentioned results and discussions, it can be concluded that:

1) Mechanical mixing is a good technique for preparing $\mathrm{Al}-\mathrm{AL}_{2} \mathrm{O}_{3}$ composite.

2) By this suggested technique in this research homogeneouse distribution of $\mathrm{AL}_{2} \mathrm{O}_{3}$ particles into $\mathrm{Al}$ matrix was achieved.

3) Both the electrical and thermal conductivities of the samples decrease by increasing the $\mathrm{AL}_{2} \mathrm{O}_{3}$ percent.

4) $5 \mathrm{wt} \% \mathrm{AL}_{2} \mathrm{O}_{3}$ sample has the lower porosity and higher density, also has the higher hardness and higher compression strength.

\section{REFERENCES}

[1] M. Kok, "Production and Mechanical Properties of $\mathrm{AL}_{2} \mathrm{O}_{3}$ Particle-Reinforced 2024 Aluminum Alloy Composites," Journal of Materials Processing Technology, Vol. 161, No. 3, 2005, pp. 381-387.

http://dx.doi.org/10.1016/i.jmatprotec.2004.07.068

[2] A. Mazahery and M. O. Shabani, "Nano-Sized Silicon
Carbide Reinforced Commercial Casting Aluminum Alloy Matrix: Experimental and Novel Modeling Evaluation," Powder Technology, Vol. 217, 2012, pp. 558-565. http://dx.doi.org/10.1016/j.powtec.2011.11.020

[3] M. O. Shabani and A. Mazahery, "Application of FEM and ANN in Characterization of Al Matrix Nano Composites Using Various Training Algorithms, Metall," Metallurgical and Materials Transactions A, Vol. 43, No. 6, 2012, pp. 2158-2165.

http://dx.doi.org/10.1007/s11661-011-1040-1

[4] A. M. Gokhale and G. R. Patel, "Analysis of Variability in Tensile Ductility of a Semi-Solid Metal Cast A356 Al-Alloy," Materials Science and Engineering: A, Vol. 392, No. 1-2, 2005, pp. 184-190. http://dx.doi.org/10.1016/j.msea.2004.09.051

[5] X. Jian, H. Xu, T. T. Meek and Q. Han, "Effect of Power Ultrasound on Solidification of Aluminum A356 Alloy," Materials Letters, Vol. 59, No. 2-3, 2005, pp. 190-193. http://dx.doi.org/10.1016/j.matlet.2004.09.027

[6] X. Chen, H. Geng and Y. Li, "Study on the Eutectic Modification Level of Al-7Si Alloy by Computer Aided Recognition of Thermal Analysis Cooling Curves," Materials Science and Engineering: A, Vol. 419, No. 1-2, 2006, pp. 283-289.

http://dx.doi.org/10.1016/j.msea.2005.12.036

[7] G. Heiberg, K. Nogita, A. K. Dahle and L. Arnberg, "Columnar to Equiaxed Transition of Eutectic in Hypoeutectic Aluminium-Silicon Alloys," Acta Material, Vol. 50, No. 10, 2002, pp. 2537-2546.

http://dx.doi.org/10.1016/S1359-6454(02)00081-2

[8] A. Mazahery and M. O. Shabani, "Influence of the Hard Coated B4C Particulates on Wear Resistance of Al-Cu Alloys," Composites: Part B, Vol. 43, No. 3, 2012, pp. 1302-1308.

[9] A. Mazahery and M. O. Shabani, "Characterization of Wear Mechanisms in Sintered Fe-1.5 Wt\% Cu Alloys," Archives of Metallurgy and Materials, Vol. 57, No. 1, 2012, pp. 93-103.

[10] M. O. Shabani and A. Mazahery, "Optimization of Process Conditions in Casting Aluminum Matrix Composites via Interconnection of Artificial Neurons and Progressive Solutions," Ceramics International, Vol. 38, No. 6, 2012, pp. 4541-4547. http://dx.doi.org/10.1016/j.ceramint.2012.02.031

[11] S. Chung and B. H. Hwang, "A Microstructural Study of the Wear Behaviour of SiCp/Al Composites," Tribology International, Vol. 27, No. 5, 1994, pp. 307-314. http://dx.doi.org/10.1016/0301-679X(94)90024-8

[12] J. S. Benjamin and M. J. Bamford, "Dispersion Strengthened Aluminum Made by Mechanical Alloying," Metallurgical and Materials Transactions A, Vol. 8, No. 8, 1997, pp. 1301-1305. http://dx.doi.org/10.1007/BF02643845

[13] M. H. Enayati and Z. Rahmani, "Fabrication of Nano Structured Al- $\mathrm{Al}_{4} \mathrm{C}_{3}$ Alloys," Materials Science and Engineering: A, Vol. 25, No. 4, 2004, pp. 515-521.

[14] S. Kleiner, F. Bertocco, F. A. Khalid and O. Beffort, "Decomposition of Process Control Agent during Mechanical Milling and Its Influence on Displacement Reaction in the 
Al-TiO System," Materials Chemistry and Physics, Vol. 89, No. 2-3, 2005, pp. 362-366.

http://dx.doi.org/10.1016/j.matchemphys.2004.09.014

[15] Z. Razavi Hesabi, A. Simchi and S. M. Seyed Reihani, "Structural Evolution during Mechanical Milling of Nanometric and Micrometric $\mathrm{Al}_{2} \mathrm{O}_{3}$ Reinforced Al Matrix Composite," Materials Science and Engineering: A, Vol. 428, No. 1-2, 2006, pp. 159-168. http://dx.doi.org/10.1016/j.msea.2006.04.116

[16] E. M. Ruiz-Navas, J. B. Fogagnolo, F. Velasco and L. Froyn, "One Step Production of Aluminum Matrix Composite Powder by Mechanical Alloying," Composites Part A: Applied Science and Manufacturing, Vol. 37, No. 11, 2006, pp. 2114-2120. http://dx.doi.org/10.1016/j.compositesa.2005.11.016

[17] C. Suryanarayana, "Mechanical Alloying and Milling," Progress in Materials Science, Vol. 46, No. 1-2, 2001, pp. 1-184. http://dx.doi.org/10.1016/S0079-6425(99)00010-9

[18] S. M. Zebarjad and S. A. Sajjadi, "Dependency of Physical and Mechanical Properties of Mechanical Alloyed $\mathrm{Al}-\mathrm{Al}_{2} \mathrm{O}_{3}$ Composite on Milling Time," Materials and Design, Vol. 28, No. 7, 2007, pp. 2113-2120. http://dx.doi.org/10.1016/j.matdes.2006.05.020

[19] M. Roy, B. Venkataraman, V. V. Bhanuprasad, Y. R. Mahajan and G. Sundararajan, "Correlation between the Characteristics of the Mechanically Mixed Layer and Wear Behaviour of Aluminium, Al-7075 Alloy and AlMMCs," Metallurgical and Materials Transactions A, Vol. 23, No. 10, 1992, pp. 2833-2846. http://dx.doi.org/10.1007/BF02651761

[20] S. Skolianos and T. Z. Kattamis, "Tribological Properties of $\mathrm{SiC}$ reinforced $\mathrm{Al}-4.5 \% \mathrm{Cu}-1.5 \% \mathrm{Mg}$ Alloy Composites," Materials Science and Engineering: A, Vol. 163, No. 1, 1993, pp. 107-113. http://dx.doi.org/10.1016/0921-5093(93)90584-2

[21] M. K. Surappa, S. V. Prasad and P. K. Rohatgi, "Wear and Abrasion of Cast Alalumina Particle Composites," Wear, Vol. 77, No. 3, 1982, pp. 295-302. http://dx.doi.org/10.1016/0043-1648(82)90055-2
[22] A. Mazahery and M. O. Shabani, "Investigation on Mechanical Properties of Nano- $\mathrm{Al}_{2} \mathrm{O}_{3}$-Reinforced Aluminum Matrix Composites," Journal of Composite Materials, Vol. 45, No. 24, 2011, pp. 2579-2586. http://dx.doi.org/10.1177/0021998311401111

[23] J. M. Torralba, C. E. daCost and F. Velasco, "P/M Aluminum Matrix Composites: An Overview," Journal of Materials Processing Technology, Vol. 133, No. 1-2, 2003, pp. 203-206.

http://dx.doi.org/10.1016/S0924-0136(02)00234-0

[24] K. H. Min, S. P. Kang, D. G. Kim and Y. D. Kim, "Sintering Characteristic of $\mathrm{Al}_{2} \mathrm{O}_{3}$-Reinforced 2xxx Series $\mathrm{Al}$ Composite Powders," Journal of Alloys and Compounds, Vol. 400, No. 1-2, 2005, pp. 150-153. http://dx.doi.org/10.1016/j.jallcom.2005.03.070

[25] Y. L. Shen and N. Chawla, "On the Correlation between Hardness \& Tensile Strength in Particle Reinforced Metal Matrix," Materials Science and Engineering: A, Vol. 297, No. 1, 2001, pp. 44-47.

[26] O. A. Elkady, M. A. Abou Tabl, Z. Abdel Hamid and S. F. Moustafa, "Processing of $\mathrm{Cu}$ /Carbon Fiber Composites by Vortex and Powder Metallurgy Technique," Canadian Metallurgical Quarterly, Vol. 46, No. 4, 2007, p. 433.

[27] A. Fathy and O. EL-Kady, "Thermal Expansion and Thermal Conductivity Characteristics of $\mathrm{Cu}-\mathrm{Al}_{2} \mathrm{O}_{3}$ Nanocomposites," Material and Design, Vol. 46, 2013, pp. 355-359. http://dx.doi.org/10.1016/j.matdes.2012.10.042

[28] E. Celebi, I. Altinsoy, T. Yener, M. Ipek, S. Zeytin and C. bindal, "An Investigation on Cemented $\mathrm{Cu}$ Reinforced by SiC Particles," Proceeding of ICAMMM 2010, Sultan Qaboos, 13-15 December 2010, pp. 13-15.

[29] A. Ibrahim, M. Abdallah, S. F. Mosatafa and A. Abousree Hegazy, "An Experimental Investigation on the W-Cu Composites," Material and Design, Vol. 30, No. 4, 2009, pp. 1398-1403. http://dx.doi.org/10.1016/j.matdes.2008.06.068 